\title{
The Development Mode of Regional Science and Technology Innovation Center Based on the Experience of China and the United States
}

\author{
Weihan Feng ${ }^{1, * \dagger}$, Jin Yan ${ }^{2, \dagger}$, Hongbo Zhang ${ }^{3, \dagger}$ \\ ${ }^{1}$ Business School, The Chinese University of Hong Kong, Hong Kong, 999077, China \\ ${ }^{2}$ College of Letters and Science, University of California, Davis, Davis, 95616, USA \\ ${ }^{3}$ School of Economics and Management, Beijing Jiaotong University, Beijing, 100081, China \\ *Corresponding author. Email: hayleyfeng@link.cuhk.edu.hk \\ These authors contributed equally.
}

\begin{abstract}
It is necessary to explore the new development mode of regional science and technology innovation center in order to boost the high-quality development. In this paper, data analysis method is used to describe the development mode and existing issues in detail based on the development experience of three high-tech innovation regions. Specifically, three regions are selected as investigation cases containing Z-Park, Silicon Valley and North Carolina's Research Triangle Park. According to the results, the establishment of a science and technology innovation center needs a perfect ecosystem, sound social network, efficient organization, strong innovation, and R\&D ability. Meanwhile, in the process of development, regional science and technology innovation center should combine with their own development reality. On this basis, they can obtain local government policy support, pay attention to the cultivation of scientific research talents, realize the integration of industry and city, and establish a livable urban community. It is of practical significance to further strengthen the construction of regional science and technology innovation center with global influence. These results shed light for the country establish a better innovation center.
\end{abstract}

Keywords: Regional innovation, Z-Park, Silicon Valley, North Carolina's Research Triangle Park, Development mode.

\section{INTRODUCTION}

\subsection{Research Background and Motivation}

Regional science park, also denoted as "science and technology park" (STP), is described as technology intensive regions, which embody research centers, business incubators, post-secondary education institutions, and technology leading firms. The innovation ecosystem embedded within each STP serves as the role of knowledge shar, innovation promoted, and research outcomes transformation (to profitable commercial products). Science parks are characterized by the "knowledge economy". The key elements of the innovation ecosystem are highly skilled workforce, corporates which capitalize ideas into production, and governments which provide policy support. Arising from "knowledge economy", nowadays STPs (innovation zones) face plenty of challenges such unaffordable rental price, loose connection between firms and universities, and ill-functioned financial system which leads inefficient capital allocation. We aim to uncover the challenges STPs faced with by examining three representative cases: ZhongGuanCun, Silicon Valley, and North Carolina Research Triangle Park. The three regional STPs are brought together for comparative analysis, and the study is to uncover the critical theoretical and practical methodologies for STPs' further development, which will provide important insights to the upgrade and transformation of each one for both academic and practitioner. The proliferation of science parks around the world, the growing importance of high technology regions' contribution to boosting national economic growth, and hyper-competitive environment in information technology, artificial intelligence, bio-medics fields motivate us into further investigating the general development pattern and prospects of three well-known STPs. Owning to its uniqueness, the three technology centers have traits in common: a 
well-established ecosystem which relies on collaboration among universities, R\&D institutes, companies, and markets; innovation culture which stimulates the knowledge flow and technology transfer between organizations; and high value-added services and facilities which promote incubation and spin-off processes of firms [1]. Apart from drawing the general pattern, the study aims to uncover the critical differences between STPs, by analyzing their pros and cons, and identifying the uniqueness of each STP's development pattern and prospect. In this case, it will provide insights into the transformation and upgrade of China's innovation ecosystem.

\subsection{Literature Review}

At present, the relevant research results of science and technology park are more and more abundant. In terms of investigating the growth of science and technology parks, Löfsten and Lindelöf [2] analyzed 273 firms on and off science parks in Sweden (1996-1998) to identify value-added elements science parks provided for new technology-based firms (NTBFs). By examining the performance of firms under 3 metrics: the study found that employment growth, sales growth and profitability, on-park firms, were better linked to local universities than off-park firms. Besides, policy initiatives to promote on-park NTBFs were likely to create more jobs than policies to support NTBFs in general. In terms of the correlation analysis between the development of science and technology parks and economic growth, Lecluyse, Knockaert \& Spithoven [3] researched on the contribution of science parks to the development and growth of technology-based firms, generation of new businesses and jobs, and regional economic prosperity. The research adopted the Input-Mediator-Outcome framework and reviewed 175 journals between 1998 and 2018. Luger and Goldstein [4] examined the economic impact of research parks in generating new businesses and jobs. The study adopted three cases: Research Triangle Park in North Carolina, Stanford Research Park in California, and the University of Utah research Park. The authors pointed out a few visions of "incubation failure" due to poor planning, lack of firm leadership, and bad luck. Luger and Goldstein concluded that old parks have captured most of the market resources, and they discussed alternative strategies for achieving better performance of the parks in a less costly way. The alternative ways stress the linkage between higher education institutes and the transformation from knowledge to jobs and profit. Recently, some scholars have also studied the relationship between the development of science and technology parks and talent attraction and stakeholders. Cadorin, Klofsten \& Löfsten [5] investigated the critical role of talents in science park's success. The study encompassed both economic and cultural contexts by sending questionnaire to 120 science parks, which collected information on parks' business data (total number of firms, employees, park management), parks' location and university collaboration rate. According to the results, the characteristics of talent contribute to the park's success. Universities are the primary source of talent, and the government has a critical role in promoting collaboration between firms and universities. In addition, some scholars have conducted research on Silicon Valley and other science and technology centers, the book published by Cambridge University Press examined the advantages of innovation in high-tech industry clusters such as Silicon Valley [6]. Benefits are summarized as following: firms' accessibility to capital, ability for venture capitalists and investment bankers to locate new investment opportunities, robust technical research capabilities of top universities, and connectivity between research institutes and corporates' commercial activities. The research attributed the benefits of regional high-tech clusters to external economies, public policy support, and well-established innovation ecosystem.

The main purpose of this study is to acquire an aggregate level of any similarities and differences (development pattern, position, downside, and prospect) among three STPs that locate near research universities. Thus, this study will explore the performance of firms located in different areas, the connectivity between corporates and universities, and the regional GDP per capita compared with the national level (cross-sectional study). In the first section (section I), we will provide rudimentary information on three STPs, including their history, development pattern, ecosystem approach, and data metrics (GDP per capita, R\&D employment, number of startups etc.) to induce the theoretical framework of our paper. Section II focuses on data analysis. We address the question by incorporating the regression model to conduct the comparative evaluation on three cases. The quantitative analysis aims to find the critical factors in STPs establishing innovation ecosystems, better transforming ideas into production, facilitating knowledge flow \& technology transfer, and improving living standard of the community. In the last section (section III), we conduct the comparative analysis based on the outcome of our regression and qualitative information on three STPs. The reason behind the success of each STP is further discussed in this section, to provide insights into ZhongGuanCun's prospects in increasing competitiveness and upgrading its innovation ecosystem.

\section{METHODOLOGY}

\subsection{Data Sources}

In order to explore a new model for the development of regional science and technology innovation centers, this paper studies the development process, current situation, advantages and disadvantages of Silicon 
Valley, ZhongGuanCun and North Carolina triangle Research Park based on the empirical data of China and the United States. Besides, we tried to study the development characteristics of regional science and technology innovation centers through the specific analysis of index data, The data sources include United States Census Bureau, National Center for Education Statistics, CBRE Tech Talent Analyzer, US EPA air quality data, Association of Bay Area Governments, Texas A\&M Transportation Institute etc.

\subsection{Data Analysis}

\subsubsection{Silicon Valley}

Silicon Valley serves as one the most notable and representative innovative STPs, thus analyzing the innovation pattern of the valley provides us an archetype for the future development of regional STPs. Investigating into Silicon Valley's innovation ecosystem helps us derive the general pattern of innovation when applying to science and technology centers universally. We incorporate five broad categories to help elaborate the valley's competitiveness and deficiencies: People, Economy, Society, Place, and Governance. Figure 1 shows the percentage of adults divided by education level. The source of the data is from the National Center for Education Statistics.

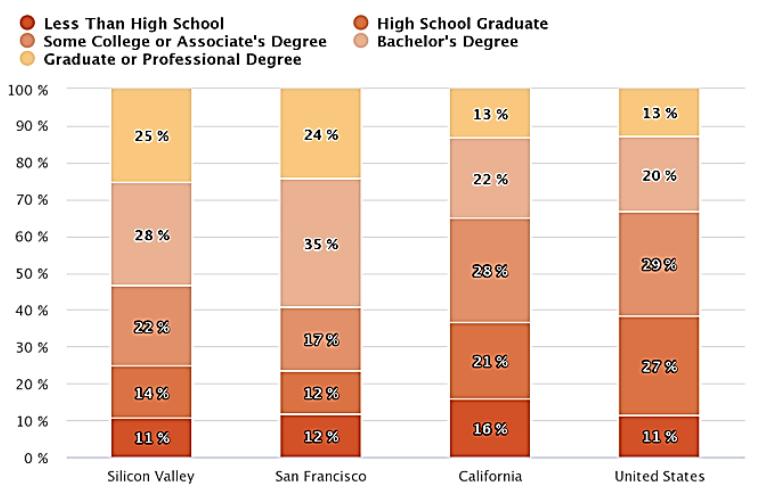

Figure1 Percentage of Adults, by Educational Attainment [7]

Figure 1 compares the level of educational attainment among Silicon Valley, San Francisco, California, and the United States. Silicon Valley's high level of education achievement contribute to the overall level of San Francisco Bay Area and California, and the region's (53\%) percentage of attaining bachelor's degree or above is significantly higher than the average US level $(33 \%)$. This shows that the level of education in the high-tech innovation area of Silicon Valley is relatively high, which matches the educational level required for high-tech development.

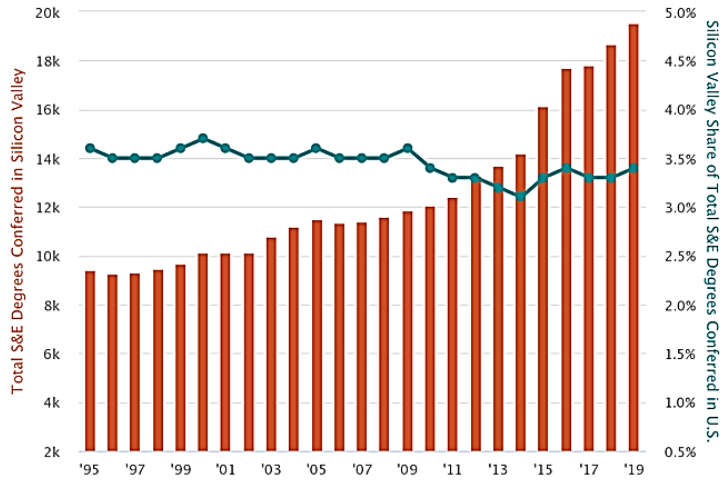

Figure2 Total Science \& Engineering Degrees Conferred [7]

Figure 2 demonstrates the total science \& engineering degrees conferred from 1995 to 2019. The source of the data is from National Center for Educational Statistics, IPEDS. The graph shows a rising number of S\&E degrees, reaching 19,000 in 2019. The increasing number of degrees conferred indicates the continuous supply of technical and engineering talents, which contributes to the leading development of information technology sector in the valley.

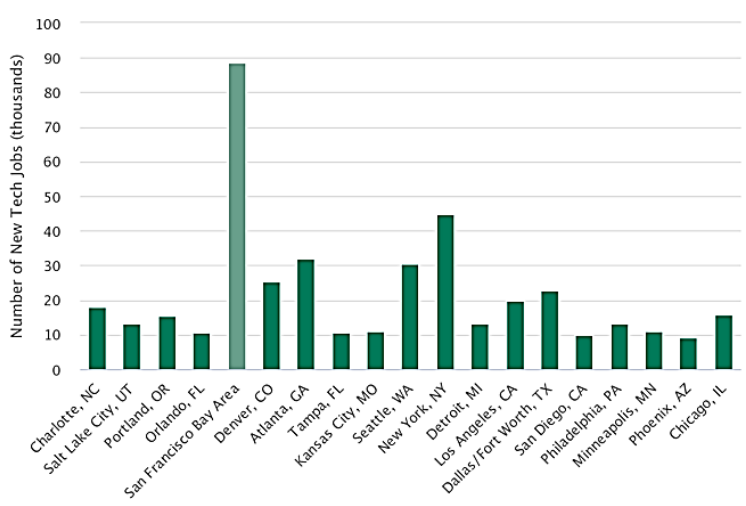

Figure3. Growth of Tech Talent in Top U.S. Tech Talent Centers [8]

Figure 3 demonstrates the growth of new tech talent in top US tech-talent centers. The source of the data is from CBRE 2019 Scoring Tech Talent Analyzer. The San Francisco Bay Area, which overlaps with the valley, hits the highest growth rate among all centers, mounting to 90,000 increases in new tech jobs. This data presents the comparatively dynamic inflow of high-skilled S\&E workforce into the valley, contributing to the ongoing innovative process. 


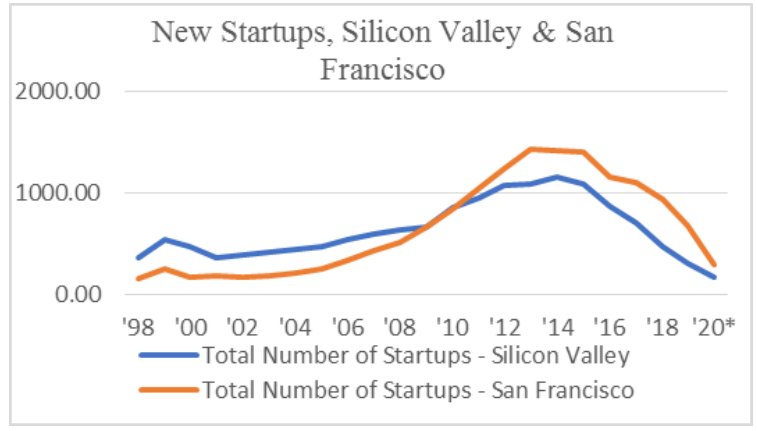

Figure4. Number of New Startup Companies

Figure 4 presents the change trend of the number of new companies in Silicon Valley and San Francisco from 1998 to 2020. The data comes from Crunchbase. It can be seen from the figure that the number of new companies reached the maximum around 2015, from 1998 to 2014. The company's large-scale expansion stage was shown in 2010. Before 2010, the number of new companies in Silicon Valley was always higher than that in San Francisco. In 2016, the number of new companies in Silicon Valley was lower than that in San Francisco. This shows that the company has no longer pursued blindly in recent years. The increase in quantity has begun to focus on quality management. At the same time, this conclusion can also be reflected in the change trend graph of the number of patents in Silicon Valley in Figure 5.

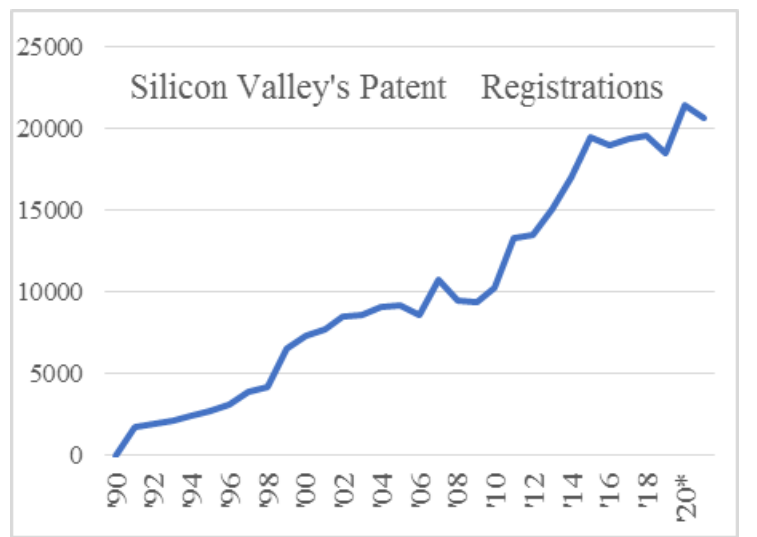

Figure 5 Total Number of Patent Registrations, Silicon Valley

It can be seen from Figure 5 that the number of patent registrations in Silicon Valley has shown an overall upward trend, and the growth rate is relatively large. Patent registrations serve as a significant indicator of a region's innovation capacity and the ability for institutes or individuals to commercialize the ideas. In 2020 , the number has reached over 20,000, representing the increasing innovative strength in the area. The upward sloping curve also projects the prospective innovation results in the upcoming years. Becoming the world's high-tech innovation center laid the foundation for scientific research. The data is collected from United States Patent and Trademark Office.

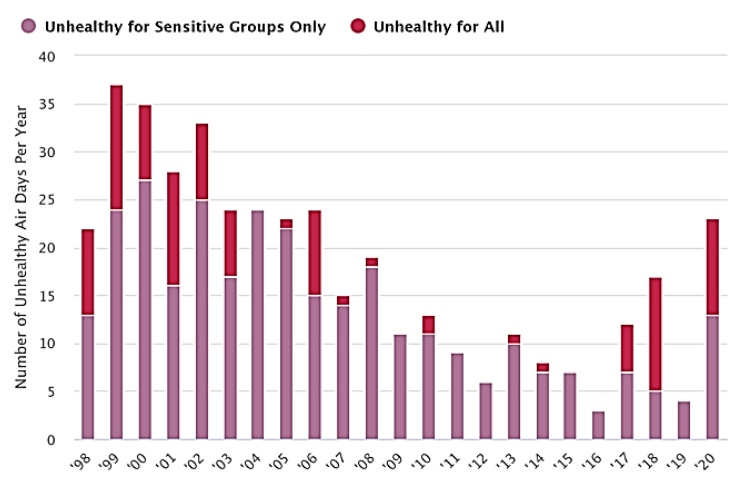

Figure 6 Number of Unhealthy Air Days [9]

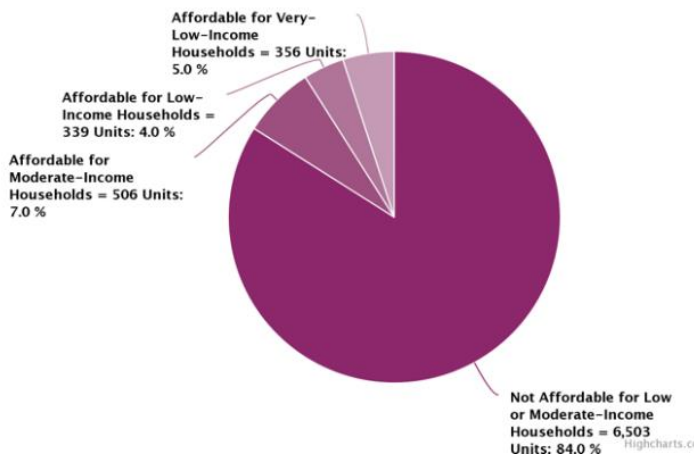

Figure 7 Housing Affordability [10]

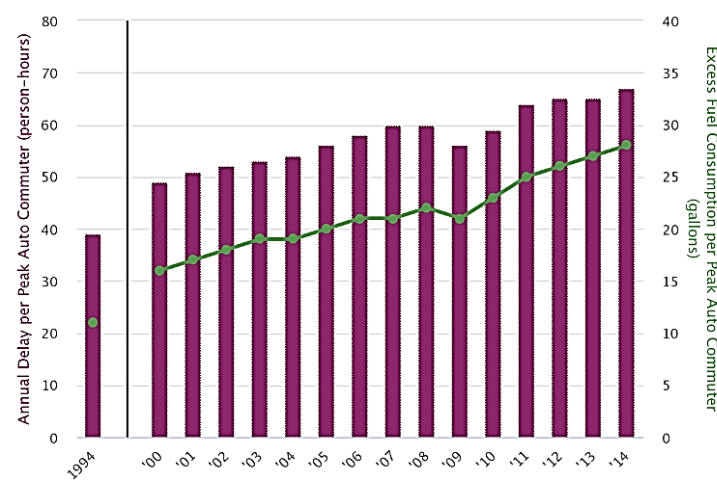

Figure 8 Time Lost to Traffic Congestion [11]

Despite the substantiated advantages of Silicon Valley, the area also faces challenges and issues in terms of environment, society, and governance (ESG). Figure 6 shows the number of unhealthy air days from 1998 to 2020, and the graph displays a rising trend since 2016, with number of unhealthy days for all increasing as well (excluding 2019). Figure 7 is closely related to habitants' living quality, as the percentage of low or moderate-income households not able to afford the housing unit accounts for $84 \%$ in the group. Figure 8 is particularly related to the governance and management of cities, in 2014, the time lost to traffic congestion annually mounted to over 65 hours, indicating lower attraction for talents or big firms to move in. 


\subsubsection{ZhongGuanCun (Z-park)}

ZhongGuanCun (Z-park) is a typical Chinese-style innovation park characterized by solid government guidance. As a follower of Silicon Valley initially, government plays an essential role in the business cycle in Z-park, which is different from Silicon Valley. However, unlike another government-led city Tsukuba in Japan, Z-park has been fully marketed. The study of Z-park should start with its history. After 40 years of rapid development since its establishment, Z-park has gone through four main periods and is now the number one innovation center in the Asia-Pacific region.

In the first phase, 1980-1988, it is Electronics Street. Each enterprise university research institution in the region was working separately, and the aggregation effect was small. The second phase, 1988-1999, is Beijing New Technology Industrial Development Trial Zone. During this period, Z-park developed rapidly and formed the initial advantages of gathering. By the end of 1998 , the regional economic output value of Z-park accounted for $14.3 \%$ of the total output value of Beijing. The main advantages of Z-park at this time were policy and capital. The third phase, 1999-2009, is ZhongGuanCun Science Park. Approved by the State Council, the Beijing government, and the Ministry of Science and Technology further expanded the Z-park. The fourth phase, 2010-present, is China National High-Tech Industrial Development Zone (Z-Park), which has gradually matured with the support of the State Council and the central government aiming to become a world-class innovation center.

Contemporarily, the development of ZhongGuanCun has achieved remarkable results, the number of high-tech innovation companies has increased year by year, and the number of patent applications has also shown an upward trend. The Figure 9 depicts a steady rise in the number of new high-tech startups in Z-park from 2008 to 2018. In 2018, the number of high-tech startup companies has reached 32000 .

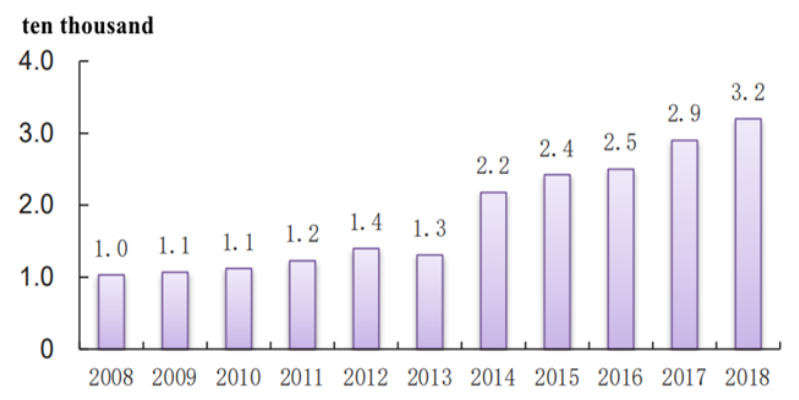

Figure 9 Number of New High-tech Startup Companies, Z-park [12]

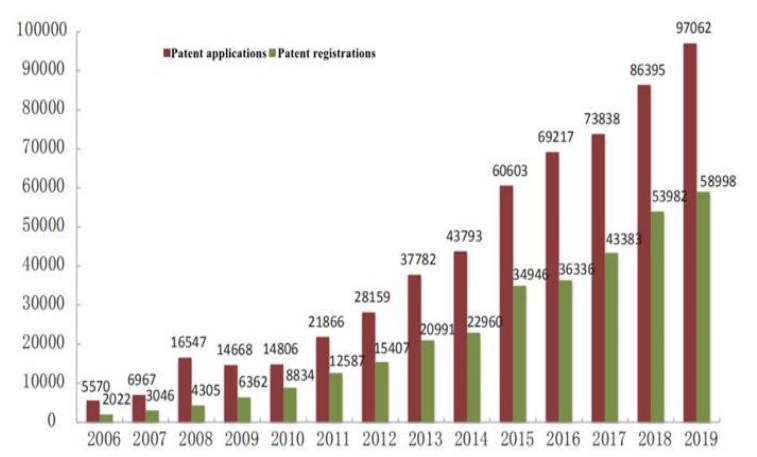

Figure 10 Totally Number of Patent Applications and Registrations, Z-park [12]

The Figure 10 reveals that there has been a gradual increase in the number of patent applications and registrations in Z-park from 2006 to 2019. Both data sources from ZhongGuanCun Statistical Yearbook. What stands out in these two figures is the phenomenal growth of Z-park. The ability of innovation will probably increase steadily after 2020 .

A short review of the history reveals that Z-park's development cannot realize without the strong support of governments at all levels, including the Haidian District, Beijing, the Ministry of Science and Technology, and the State Council. These supports have cleared political barriers to Z-park's development, and typical examples include Z-park's ability to develop its unique talent attraction policies.

Z-park has an entire policy support system of $1+4$ to help companies, mainly innovative companies, develop and meet their needs. In the growth stage, it could enhance value creation and delivery. According to Anna Trunina, Shayegheh Ashourizadeh [13], Z-park meets the needs for socioeconomic development. Unlike other innovation parks where companies are free to develop, Z-park has more support for companies that meet social development needs, e.g., Covid-19 vaccine, high-speed trains technology, and 5G technology. Although it is difficult for these companies to make commercial profits quickly, these technologies are vital to social development. Z-park has a strong focus on regional collaboration and assistance. A typical example is Yinchuan- ZhongGuanCun Innovation Center, a relatively small and poor city located in the interior of China, $890 \mathrm{~km}$ away from Beijing, which is generally difficult for z-park's innovative companies to notice. However, through regional cooperation, Z-park has opened up a new market and business opportunities for companies. As a result, the famous education-technology company New Oriental has reportedly established a branch and gained a new market of 2 million people.

However, the current development model of China Customs Standards still has certain drawbacks, e.g., the lack of innovative talents in the park, fierce market 
competition. Meanwhile, the innovation awareness of researchers needs to be improved. In addition, due to the existence of government subsidies and policy support, enterprises tend to form the sense of dependence has led to low operating efficiency and reduced product innovation capabilities. Compared with the world's top innovation regions, there is still a large gap in innovation conversion rate.

\subsubsection{North Carolina's Research Triangle Park}

North Carolina's Research Triangle Park is a rare large-scale high-tech park actively guided and promoted by the government in the United States. It has made remarkable achievements. Through its development mode and process, this paper summarizes the following main characteristics. Early North Carolina was an agricultural state, lacking strong industrial tradition and external demand. For example, the early defense needs of Silicon Valley. Facing the pressure of economic development, the local government and all walks of life put forward the construction plan of the park based on the demand of providing employment and increasing income [14]. Secondly, in the initial stage of implementation, in the face of various difficulties, the government also provides important support and coordination in land and funds. However, the government did not directly manage the affairs of the park but set up the Research Triangle Foundation (RTF) to make it fully operate and manage the park. The Foundation Committee is composed of representatives from the third party and is clearly defined as a non-profit organization. The committee discusses major strategies and decisions and employs professionals to operate the market. The foundation rents or sells the land of the park to the enterprises, and is responsible for taxing the enterprises in the park. Firms in the park do not have to pay taxes to the state government. Then, the foundation will use the income to invest in or improve the facilities of the science park. The foundation will also attract more enterprises through professional targeted information releases or association with domestic enterprises. Besides, the foundation also cooperates with foreign universities, research institutions, and science and technology parks to expand the popularity of the park. In addition, the government's support is also reflected in its positive actions, e.g., assisting RTF to provide park infrastructure, helping to attract investment, connecting enterprises and universities, as well as in its tax incentives. With the continuous support of the government, a good business environment in the park has been formed.

In the process of development, while formulating and implementing various powerful policies, they continue to promote the establishment of the various cross-university and cross-enterprise research institutions and promote the transformation of scientific research and industry. RTP has a complete innovation generation system and give full play to their advantages as well as form a collaborative innovation situation through the open innovation platform to link all the main body together. The subjects of innovation include research universities: the University of North Carolina at Chapel Hill, Duke University, and North Carolina State College of Agriculture; Startup business incubators, e.g., The Lab, First Flight, etc.; Large mature enterprises, e.g., Lenovo and other electronic information enterprises, general electric and other manufacturing enterprises; Market-oriented research institutions, e.g., IBM Global Research Center, National Institute of Environmental Health Sciences, etc.; Public-private partnership management organizations, e.g., the government, enterprises, and schools, form the board of directors to be jointly responsible for the management and operation of the park. By comparing the data in Figure 11 and Figure 12, it can obviously see that the income of Non-farm enterprises and individuals has been increasing in recent years [15]. However, the income of farm enterprises and individuals is relatively stable. Nevertheless, it is not difficult to see that the income of non-farm practitioners is much higher than that of farm practitioners, which also verifies the successful transformation of Carolina, who used to rely mainly on agriculture.

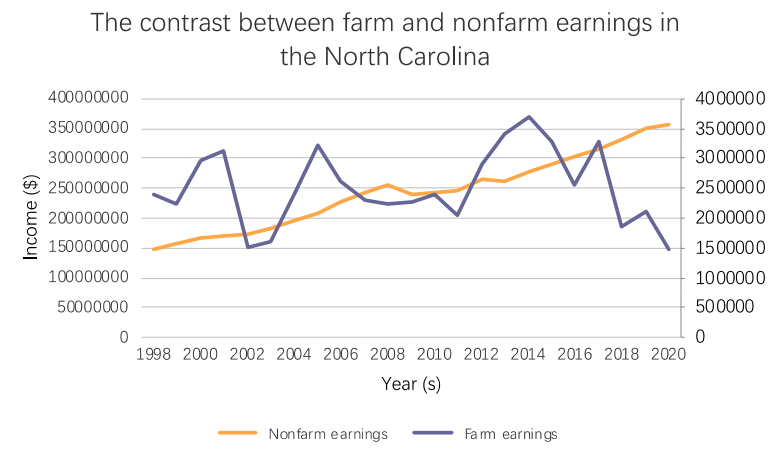

Figure11 The contrast between farm and nonfarm earnings in the North Carolina

The contrast between farm proprietors' income and nonfarm proprietors' income in the North Carolina

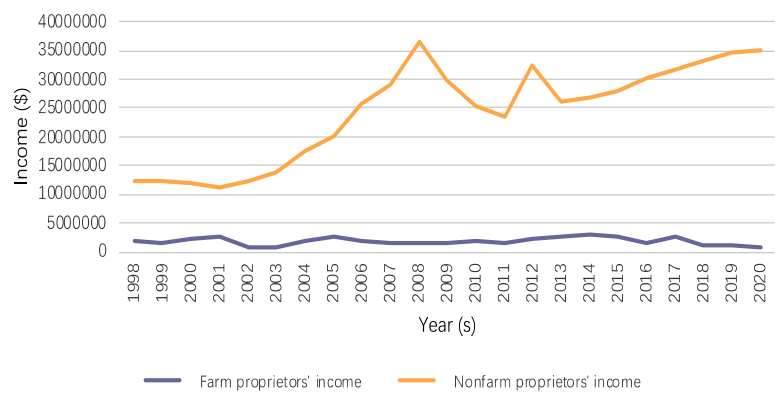

Figure12 The contrast between farm proprietors' income and nonfarm proprietors' income in the North Carolina 
Figures 11 and 12 are the comparison graphs of agricultural income and non-agricultural income, farmer income and non-farm income, respectively. It can be seen from the figure that the changes in agricultural income and farmer income are very small, and basically remain unchanged. The income of non-agricultural and non-farm owners has changed greatly, and the overall trend is increasing.

RTP has six incubators, the core of which is the park research center founded by the research triangle foundation. The park research center has 13 buildings [16]. It is the area where high-tech companies are concentrated in the entrepreneurial stage. The Park research center has obvious rent advantages. In addition, it also provides comprehensive supporting facilities and administrative services. The incubator represented by "Park Research Center" in the park has rich experience and mature operation, which promotes the sustainable development of entrepreneurial enterprises in the park. With the support of many experienced and mature incubators in the park, RTP's start-ups continue to develop and become an important force to drive the innovation and development of the park and even the upgrading and development of regional industries. Based on maintaining the establishment of high-tech industrial R\&D centers, rather than the development keynote of production sites. The industrial types developed in the park are rich and diversified (seen from Figure 13), and the development focus becomes flexible with the progress of the times and science and technology. After IBM joined, it focused on the development of the electronic industry. Since the 1980s, they have focused on the development of microelectronics and bioengineering. After the 1990s, the focus turned to network engineering and Biotechnology.

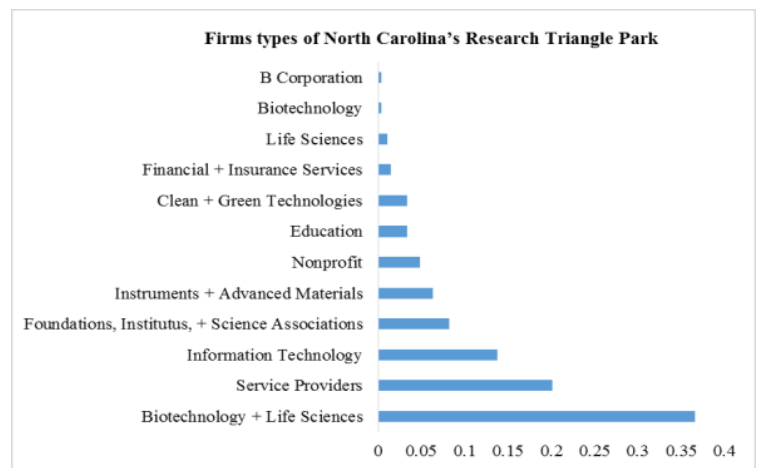

Figure13 Firms types of North Carolina's Research Triangle Park

However, there are still some challenges in RTP, e.g., how to get a firm foothold in the fierce competition of innovation and talent, and always be at the forefront of innovation. The commercial conversion rate of science and technology still needs to be improved. R\&D achievements need to be better industrialized. RTP is the research and development place of many large enterprises right now, but it lacks the ability to cultivate self-generated enterprises with a certain scale in the park. The aging of hardware facilities and equipment in the park and the improvement of residents' quality of life still need to be solved. The lack of close cooperation between enterprise clusters may waste resources. RTP needs to consider how to integrate resources in the park to maximize benefits.

\section{DISCUSSION}

Based on the development data of science and technology innovation centers in China and the United States, this paper analyzes in detail the development process, current situation and development mode of ZhongGuanCun, Silicon Valley and North Carolina triangle Research Park. Besides, it expounds the problems existing in the development of the three science and technology innovation centers, trying to summarize their future development mode and adjustment direction.

\subsection{Silicon Valley}

The success of Silicon Valley is attributed to its well-established innovation ecosystem. Combining the data collected with the interpretation results, it is noticeable that the prospect of STPs follow the general pattern of mature ones, while incorporating strategic adjustments into its innovation system. Based on the results from last section, we indicate future development pattern for STPs, with steering development orientation and feasible ways to achieve better outcomes.

Firstly, the consolidation of link among institutes and organizations. Universities, research institutes, venture capitals, mature corporations, governments, and entrepreneurs are critical elements in constructing an innovation ecosystem, and the collaboration could create a significant positive externality, with intensive synergy and knowledge spillover effect [17]. Government's policies directing organizations to cooperate could enhance the overall capability of STP to transform ideas into commercial products, while attracting more talents and academic gurus.

Secondly, an overall improvement in urban planning, construction, and management. In Silicon Valley's case, it is intuitive that the region is likely to lose attraction to big firms or talents due to high living costs (unaffordable housing units), severe environmental pollution, annoying traffic congestion, and specifically under the globalization effect, the covert discrimination against non-white workers, as corroborated in the wage gap among different racial groups. It is not only government's responsibility to make the city a livable place, but also various organizations' (profitable \& non-profitable) duty. Corporations are supposed to adhere to the ESG disciplines, in terms of reducing 
carbon emission, incorporating circular economy, eliminating the workplace discrimination, and making more social investments.

Lastly, one well-established financing system and developed financing structure favors startups, by facilitating the capital allocation process and reducing transaction costs. The mobility of capital (resources) is the key factor in determining the survival or success of new companies [18], which seeks to provide cutting-edge and disruptive technologies, as well as collaborating with larger firms for financing support and management capabilities.

\subsection{ZhongGuanCun (Z-park)}

The government plays an essential and unique role in the case of Z-park. The main aspects are as follows.

Firstly, the government of Z-park has done an excellent job of providing regular public services that are beneficial to innovation. Regardless of the country or culture, policies such as lowering tax rates, attracting talents, and maintaining good cooperation with universities and research institutions can effectively promote regional innovation.

Secondly, in terms of space, the government maintains a balanced development between innovation centers and cities by regulating the spill-over effect of innovation centers and creates a unique sub-park model. Sub-parks modal can entirely use their location advantages. City development attracts talents, talents promote innovation, and innovation drives city development. All these processes form a positive cycle.

Finally, the government provides non-traditional essential public goods and acts as an information platform using its special status in China and formal social network between governments. Companies need a variety of innovative resources in their innovation activities. In addition to technology, capital, and human resources, factors such as the goodwill of enterprises, a perfect social network, and good political and business relationship are also significant. The Z-park tries to meet the needs of enterprises in non-economic factors innovation. The Z-park government provides information and policy support for enterprises through various ways such as academic forums, salons, and exhibitions, including providing potential customers and collaborators, providing business opportunities. In the meantime, it provides potential markets, reduces political risks in multi-regional cooperation for enterprises in regional co-operations and international communications, and prepares enterprises for further development.

\subsection{North Carolina's Research Triangle Park}

The success factors of RTP can be summarized as follows. Firstly, government support and related services are the necessary prerequisites for the development of the park. Secondly, the management committee is not only the basic service provider of the park but also the operator and enterprise think tank of the park. Thirdly, a complete innovation generation system is also essential for the successful development of the park, and the park combines the direction of higher education research universities and urban economic development to achieve common progress. Fifthly, there are many kinds of industries in the park. The focus of development in the park can also become more flexible with the progress of the times and science and technology. Sixthly, it not only attracts large enterprises to join in to promote the progress of the park but also sets up several incubators to support self-generated entrepreneurial projects.

Talented people are the key to the development of science and technology. Business environment and life support are important factors to attract and retain talents. Industry city integration and the modern service industry are the future development direction of the RTP. Firstly, the old office area can be transformed, and the main purpose is the rent of the learning office area. This can provide free discussion and learning space for learners and entrepreneurs. It can also provide cost-effective office space for start-ups and other rising companies. Providing modern laboratories for enterprises and institutions with research needs, and office space for large enterprises that can accommodate more people. Secondly, building the modern pedestrian communities. The purpose is to build a new gate of the triangle area so that the residents in the park can find a balance between work and life. This area can include hotels, retail, park, office, and other residential functions. Third, build a dining and leisure area to provide all-weather rest places for nearby staff. Through these future development directions, the North Carolina Triangle Research Park will provide higher-quality residential and commercial facilities for the park residents. It also provides modern and cost-effective intensive office space for enterprises, to attract large enterprises to settle. This can help entrepreneurs with their dreams and change the decentralized layout of previous organizations. It can also enhance the official and unofficial interaction and contact of groups of people and enterprises, and eventually, help the collaborative development of industry-university research.

\section{CONCLUSION}

In summary, the two major tends of knowledge and globalization are reshaping city functions, rebuilding both global technology and economic territories, and boosting the formation of a global innovation network. 
Additionally, building a regional science and technology innovation center with global impact has increasingly become a major strategy for many countries and regions to enhance their comprehensive strength to cope with a new round of science and technology revolution. This article explored the developmental experience of Z-park, Silicon Valley, and North Carolina Research Triangle Park, and deeply went through the patterns and problems of those three iconic technology innovation centers. Based on the results, their development not only relies on technology, capital, and human resources, but also needs helps with governmental support, ability in innovation, and ability to attract innovative entrepreneurs., it also demands a well-constructed innovation ecosystem, a healthy social network, and good relationships with both government and business connections. As the market operation of international technology and capital transfer is maturing, countries should fully utilize the results of worldwide technology achievement and global capital market, find and combine their unique advantages in resources as well as refine company and institute organizations. Moreover, it is necessary to put more attention on creating and keeping talents, use results from universities and research institutes, strengthen ability to innovate, frame innovation network, renew innovation pattern, improve innovation level, take advantage of modern digital technology, digital finance, and digital economy to achieve confusion of production and city, build communities, and gain a long-term stay of the talented minds. This research has amplified the result of research of technology innovation development, and emphasized the practical meaning of building regional technology center for the regional economy and domestic development simultaneously. These results offer a guideline for the country or state establish a better innovation center.

\section{REFERENCES}

[1] IASP: Global Network of Science \& Technology Parks \& Innovation Districts - IASP. (2016). International Association of Science Parks and Areas of Innovation. https://www.iasp.ws/

[2] Löfsten, H., \& Lindelöf, P. (2002). Science Parks and the growth of new technology-based firms - academic-industry links, innovation and markets. Research Policy, 31(6), 859-876. https://doi.org/10.1016/s0048-7333(01)00153-6

[3] Lecluyse, L., Knockaert, M., \& Spithoven, A. (2018). The contribution of science parks: a literature review and future research agenda. The Journal of Technology Transfer, 44(2), 559-595. https://doi.org/10.1007/s10961-018-09712-x

[4] Technology in the Garden, Michael I. Luger and Harvey Goldstein. 1991. University of North
Carolina Press, Chapel Hill, NC. (1993). Bulletin of Science, Technology \& Society, 13(3), 171. https://doi.org/10.1177/027046769301300363

[5] Cadorin, E., Klofsten, M., \& Löfsten, H. (2019). Science Parks, talent attraction and stakeholder involvement: an international study. The Journal of Technology Transfer, 46(1), 1-28. https://doi.org/10.1007/s10961-019-09753-w

[6] Bresnahan, T., \& Gambardella, A. (2010). Building High-Tech Clusters: Silicon Valley and Beyond. Cambridge University Press. https://doi.org/10.1017/CBO9780511802911

[7] The Integrated Postsecondary Education Data System. (2020). National Center for Education Statistics. https://nces.ed.gov/ipeds/use-the-data

[8] Tech Talent 2019. (2019). CBRE Tech Talent Analyzer. https://mapping.cbre.com/maps/Scoring-Tech-Tale nt-2019/

[9] Outdoor Air Quality Data. (2021). US EPA. https://www.epa.gov/outdoor-air-quality-data

[10] Association of Bay Area Governments. (2021). Association of Bay Area Governments. https://abag.ca.gov

[11] Urban Mobility Report. (2015). Texas A\&M Transportation Institute, Urban Mobility Information. https://mobility.tamu.edu/umr/

[12]Yearbook of Zhongguncun. (2020). Administrative Commission of Zhongguancun Science Park. https://www.zgcyqz.cn/

[13] Trunina, A. and S. Ashourizadeh, Business model-network interactions: Comparative case studies from Zhongguancun and Silicon Valley. Technology in Society, 2021. 65: p. 101600.

[14] The Foundation. Research Triangle Park. (n.d.). https://www.rtp.org/the-foundation/.

[15] Bureau of Economic Analysis. U.S. Bureau of Economic Analysis (BEA). (n.d.). https://www.bea.gov/.

[16] Link, A.N., Scott, J.T. The Growth of Research Triangle Park. Small Business Economics 20, 167175

(2003). https://doi.org/10.1023/A:1022216116063

[17] Engel, J. S. (2015). Global Clusters of Innovation: Lessons from Silicon Valley. California Management Review, 57(2), 36-65. https://doi.org/10.1525/cmr.2015.57.2.36

[18] Deloitte University Press. (2016). How to innovate the Silicon Valley way: Tapping into the Silicon Valley ecosystem. https://www2.deloitte.com 